\title{
The relationship among the age at menarche, anthropometric characteristics, and socio-economic factors in Bengali girls from Kolkata, India
}

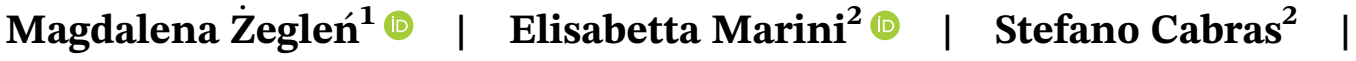 \\ Eukasz Kryst $^{1}$ ( ) | Rituparna Das ${ }^{3}$ | Anindita Chakraborty ${ }^{3}$ | Parasmani Dasgupta ${ }^{3}$
}

\author{
${ }^{1}$ Department of Anthropology, Faculty of \\ Physical Education, University of Physical \\ Education in Kraków, Kraków, Poland \\ ${ }^{2}$ Department of Life and Environmental \\ Sciences, University of Cagliari, Cagliari, \\ Italy \\ ${ }^{3}$ Biological Anthropology Unit, Indian \\ Statistical Institute, Kolkata, India

\section{Correspondence} \\ Łukasz Kryst, Department of \\ Anthropology, Faculty of Physical \\ Education and Sport, University of \\ Physical Education, 31-571 Kraków, \\ Poland. \\ Email: 1kryst@poczta.onet.pl \\ Elisabetta Marini, Department of Life and \\ Environmental Sciences, University of \\ Cagliari, Cagliari, Italy. \\ Email: emarini@unica.it \\ Funding information \\ Neys van Hoogstraten Foundation, Grant/ \\ Award Number: ID158; Indian Statistical \\ Institute
}

\begin{abstract}
Objectives: The aim of the study was to measure the causal effect of selected socio-economic factors and anthropometrical characteristics on the menarche occurrence.

Methods: The sample consisted of 2195 Bengali girls (aged 7-21) from middleclass families, from Kolkata city, India. The age at menarche was recorded from the retrospective data and status quo method. The causal effect of anthropometric and socio-economic variables on menarche occurrence was estimated by the nonparametrical analysis of survival probability (survival random forest).

Results: In the examined cohort menarche occurred, on average, at 11.8 years of age. The probability of menarche occurrence amplified with the increasing values of factors such as body mass index, height-for-age $z$-scores, number of family members, household rooms, and toilets, but decreased when expenditures increased. The relation maintained a similar pattern of causal effect with girls' age.

Conclusions: A complex pattern of relationship among sexual development, physique, and socio-economic characteristics was defined. The tendency toward early menarche, along with the observed causal relationships indicate that the analyzed sample is nearing the characteristics and standards of living noted in other middle and even high-income countries in the world.
\end{abstract}

\section{1 | INTRODUCTION}

The age of the biological maturation is vital for both the physical and psychological health of girls and young women. In fact, too early and too late onset of biological maturation can have negative effects. The premature occurrence of menarche is associated with a higher risk of obesity, breast and ovarian cancer, anxiety, depression, as well as metabolic syndrome (WHO, 2000). On the other hand, the too late onset of menarche is correlated with a higher risk of, once again, metabolic syndrome, but also oligomenorrhea and cardiometabolic abnormalities (Glueck, Morrison, Wang, \& Woo, 2013).
The age of menarche occurrence is influenced by many factors. Among others, they include woman's genetic background, as in the human genome, there are 10 single nucleotide polymorphisms, located in two loci, which have a significant impact on the onset of menarche (He et al., 2009). In addition, later studies suggest the presence of even 30 to 40 more loci containing genes with an analogous function (Elks et al., 2010).

Many of the genes that are crucial in regulating the onset of menarche are also significant for the hormonal regulation, energy homeostasis, as well as the determination of body height or weight (Elks et al., 2010). Moreover, it has been suggested that the height and weight of 
the body, as well as their mutual proportions also pose important constraints (Anderson \& Must, 2005; Fredriks et al., 2005; Gohlke \& Woelfle, 2009; Talma et al., 2013). Because of that, the so-called "critical weight theory," where a certain body mass must be gained for the menarche to occur, was proposed (Frisch \& Revelle, 1970). However, in later years, it was suggested that the presence of leptin, as well as the other hormones related to energy management, can also have a decisive role (Fernandez-Fernandez et al., 2006; De Bond \& Smith, 2014). Due to the described phenomena, girls with higher weight and body adiposity generally experience menarche earlier than their leaner peers (Chowdhury et al., 2000; Khatoon et al., 2011).

On the other hand, the moment of menarche occurrence can influence some of the anthropometric features. In fact, it has been proven that girls who experience earlier menarche reach a shorter adult height (Gharravi, Marjani, \& Golalipour, 2008). It is also generally suggested that the earlier biological maturation is correlated with a higher subsequent body mass index (BMI; Laitinen, Power, \& Järvelin, 2001; Parsons, Power, Logan, \& Summerbell, 1999; Pierce, Kuh, \& Hardy, 2012; Pierce \& Leon, 2005). Due to its close association with the growth process menarche status is considered more informative than anagraphic age about the body composition changes and biological development in adolescent girls (Buffa, Floris, \& Marini, 2002; Buffa, Floris, Marini, \& Ortu, 2003; Koury, Ribeiro, Massarani, Vieira, \& Marini, 2019).

Other factors affecting the onset of menstruation include the socio-economic environment, such as, for example, the social class (Bagga \& Kulkarni, 2000; Wronka \& PawlińskaChmara, 2005). Moreover, family size, or living conditions, among others, can be distinguished as crucial factors influencing the age of biological maturation (Khalid et al., 2015). Due to its recognized sensitivity to environmental factors, age at menarche can be considered an indicator of changing socio-economic conditions. Therefore, it is a common subject of research concerning intergenerational changes. The negative secular trend regarding the age at menarche was observed in many countries. This phenomenon is one of the effects of the socio-economic progress, significant especially in developing countries, such as India, as acceleration of biological maturation is correlated with the improvement of the living conditions of people (Cole, 2003; International Statistical Institute, 2017; Kowal, Kryst, Woronkowicz, \& Sobiecki, 2014; Das et al., 2016; Kryst, Kowal, Woronkowicz, Sobiecki, \& Cichocka, 2012; Meng, Li, Duan, Sun, \& Jia, 2017).

The aim of the study was to measure the causal effect of the selected socio-economic factors and anthropometrical characteristics on the menarche occurrence in a large sample of middle-class, Bengali girls.

\section{2 | MATERIALS AND METHODS}

\section{1 | The sample}

A cross-sectional sample of 2195 girls of Bengali population aged 7 to 21 years (Table 1), from 66 schools and colleges from Kolkata city, India, has been collected during one survey period (2005-2011). Girls' calendar age was calculated as a difference between the date of the survey and the birth date, which was expressed as a decimal fraction. Each child was then classified into one of the age categories on the basis of the said calendar age (eg, the group of 7 year-olds included children whose calendar age ranged from 6.50 to 7.49 ).

The girls came predominantly from middle-class families, classified as such on the basis of:

- monthly family expenditure- $\geq 2200$ INR;

- parental occupation-majority of fathers working in business field;

- parental education-majority had at least graduate degree;

- household assets and housing condition-included for example the area occupied by the household, number of rooms ( $\geq$ in majority of the cases and bathrooms (at least 1) in the house as well as the source of drinking water (own tap/well in majority of the households).

T A B LE 1 Age distribution of the sample of 2195 girls of Bengali population

\begin{tabular}{|lll|}
$\begin{array}{l}\text { Age } \\
\text { group }(\mathbf{y})\end{array}$ & $\begin{array}{l}\text { Number of } \\
\text { individuals } \mathbf{( N )}\end{array}$ & $\begin{array}{l}\text { N in which menarche } \\
\text { occurred }\end{array}$ \\
\hline 6 & 48 & 0 \\
\hline 7 & 159 & 0 \\
\hline 8 & 165 & 2 \\
\hline 9 & 153 & 8 \\
\hline 10 & 147 & 19 \\
\hline 11 & 141 & 61 \\
\hline 12 & 162 & 124 \\
\hline 13 & 113 & 104 \\
\hline 14 & 149 & 144 \\
\hline 15 & 137 & 137 \\
\hline 16 & 160 & 160 \\
\hline 17 & 131 & 131 \\
\hline 18 & 130 & 130 \\
\hline 19 & 131 & 131 \\
\hline 20 & 183 & 183 \\
\hline 21 & 86 & 86 \\
\hline Total & 2195 & 1420 \\
\hline & & \\
\hline
\end{tabular}


The qualification to the research group was based on the good overall health of the girls and the consent of their parents or legal guardians. All procedures contributing to this work comply with the ethical standards of the relevant national and institutional committees on human experimentation and with the Helsinki Declaration of 1975, as revised in 2008.

\section{2 | The variables}

The analyzed anthropometric characteristics included body height and weight, measured according to the protocol of the International Biological Program (Weiner \& Lourie, 1969), using an anthropometer (GPM, Switzerland; accuracy $1 \mathrm{~mm}$ ) and electric weight (Libra, India; accuracy $0.1 \mathrm{~kg}$ ). Height was expressed as height-for-age $z$-scores (HAZ), calculated according to WHO standards (de Onis et al., 2007) and BMI (body weight $[\mathrm{kg}] /$ body height $\left[\mathrm{m}^{2}\right]$ and as BMI $z$ scores [BAZ]). The analyzed socioeconomic characteristics of children's families included: number of family members, sibship size and parity, family type, parents' occupation and education, family expenditure, caste, number of rooms and toilets in the house, household duration, house possession, as well as drinking water source distance and adequacy.

\section{3 | STATISTICAL ANALYSIS}

\section{1 | Age of menarche}

The status quo and retrospective recall methods have been applied. The status quo method allows defining the "current status" regarding the birth date and menarche occurrence at the time of assessment (yes or not) by asking a girl (or her parent). The retrospective recall method allows the definition of menarche age by asking postmenarchal females (or their parents) to recall the date of first menses.

Age at menarche in the whole sample has been evaluated by means of a survival curve estimated from the Kaplan-Meier estimator (Klein \& Moeschberger, 2003).

\section{2 | Influential factors of the age of menarche}

The causal effect of socio-economic and anthropometric variables on the age of menarche was analyzed using the survival random forest (SRF) model (Breiman, 2001; Mogensen, Ishwaran, \& Gerds, 2012). SRF is a nonparametric survival regression method suitable for large datasets, as in this research, in which no linear predictor (ie, all variables along with all their interactions) has to be specified beforehand and where all possible interactions among all considered confounding factors can be accounted for. Hence, the analysis represents a significant improvement with respect to ordinary regression approaches, either for modeling or for estimating causal effects. In particular, as shown by Lu, Sadiq, Feaster, and Ishwaran (2018), SRF allows to measure causal effects also in cross-sectional samples. Such inference on the individual causal effect is obtained by means of the difference between the factual observed age at menarche (for the group of girls with menarche) and the counterfactual value (age at menarche estimated using SRF and variable values of the anthropometric or socio-economic variables). This difference represents an estimate of the individual causal effect due to the anthropometric or a socio-economic intervention variable. The means of such differences are used to estimate overall causal effects (for more details: Gelman \& Meng, 2004). In this research, the analysis has been based on the survival curve of age at menarche in the whole sample. Causal effects have been estimated by assuming that the SRF model is able to predict the age of menarche, under a large set of possible causing variables. The possible error in menarche age due to the recall method has been accounted for by introducing the girls' age (assumed to be related to retrospective data) as a confounding effect.

\section{4 | RESULTS}

\section{1 | Age of menarche}

The majority of girls in the sample $(1420 ; 64.7 \%)$ had experienced menarche at the time of data collection: 715 girls recalled the age of menarche with an approximation no larger than 1 month (day, month, and year, or month and year), 22 with an approximation no larger than 6 months (1-6 months), 195 remembered the year only, and 488 did not mention any date (Table 1).

The estimated median age at menarche of girls calculated from status quo data by Probit analysis was 11.6 years. Considering retrospective data of girls who remembered the exact age with an error lower than 1 month $(\mathrm{N}=715)$ the mean age of menarche was $11.8 \pm 1.2$.

Figure 1 represents the empirical marginal survival curve up to menarche event, that is, the probability of not having menarche at a given age.

\section{2 | Influential factors on age of menarche}

The model estimating the causal effect on age of menarche occurrence due to the specified anthropometrical 
(BMI, BAZ, HAZ) and socio-economic variables (family expenditure, family members, sibship size, parity, family type, household rooms, household toilets, household duration, parents' occupation and education, caste, house possession, drinking water source, distance, and adequacy) was quite explicative (variance explained of the above survival curve: $67.1 \%$ ).

Figure 2 represents the possible causal effect of selected factors on age of menarche occurrence, that is, the proportion of girls in which menarche occurred

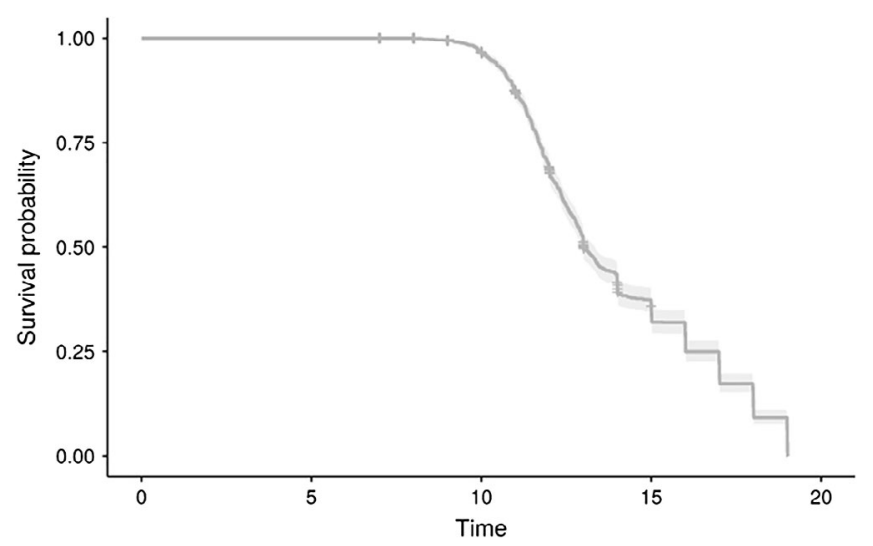

F I G URE 1 Curve of empirical survival probability up to menarche occurrence according to factors variation, given fixed the effect of all other covariates (assumed as confounders). The age of 12 years, near the mean age of menarche, was selected to show these results. As can be seen, the probability of menarche occurrence at age 12 significantly increased (the survival, that is, the proportion of girls without menarche, decreases) with increasing values of BMI, BAZ, HAZ, number of family members, household rooms, but decreased when expenditures increases, while household duration did not show a significant effect. In particular, for example, the probability of menarche occurrence shifted from around 0.31 to 0.40 , when BMI values changes from 15 to 27, indicating that higher values of BMI induce more precocious menarche. The probability also increased with the number of household toilets, sibship size, and parity, and decreased in case of household possession and adequate drinking source (Figure 3). Furthermore, a higher probability of menarche occurrence was perceived in girls whose parents attended a college, whose fathers were retired, who pertained to the "other backward class" caste, while the probability was lower among girls whose parents were graduated and whose mothers were working in business areas. Household duration (Figure 2), family type, and drinking water source distance seemed not to have a significant role in age of menarche occurrence in this sample of Indian girls.

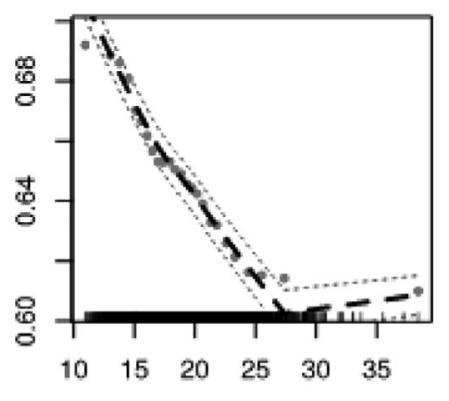

BMI

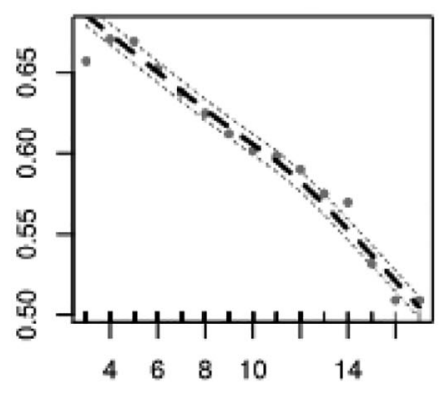

No. of family members

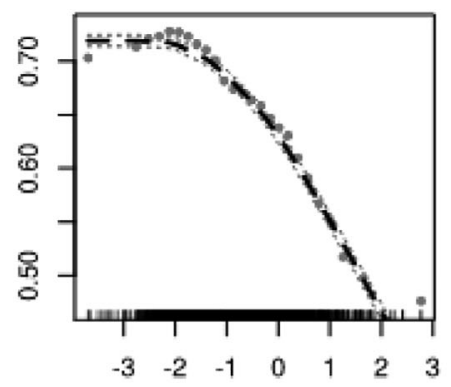

HAZ

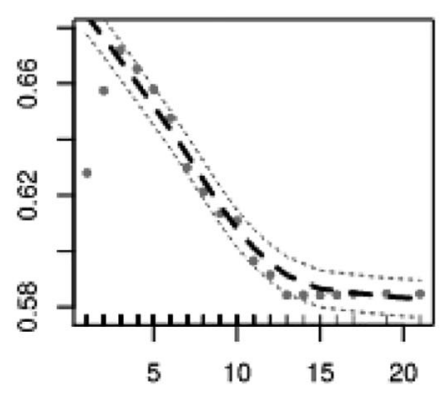

No, of rooms in the households
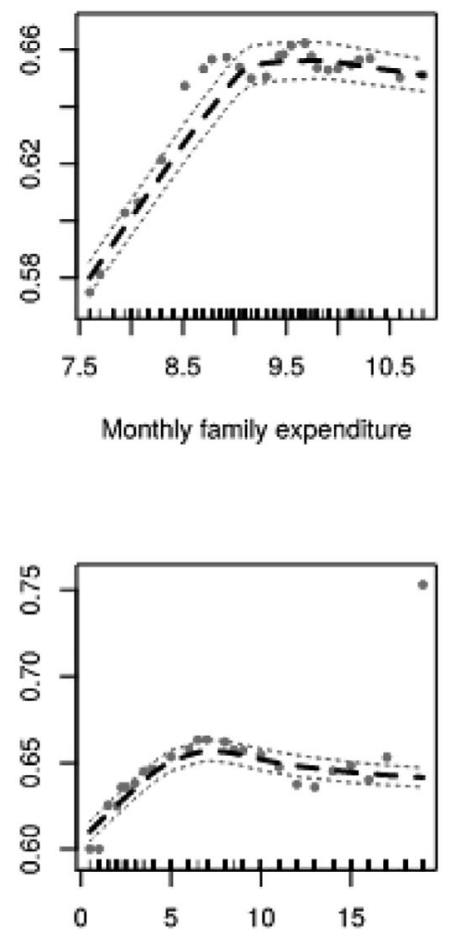

Duration of stay in the households

F I G U RE 2 Survival probability up to menarche occurrence according to different causal factors. Vertical axis is the estimated survival probability up to menarche onset at 12 years (ie, the higher, the less probable is menarche onset) 
Interestingly, the relations maintained a similar pattern of causal effect with girls' age, even in some cases changing the scale of survival probability. For example, considering BMI, the peak of greater probability of menarche occurrence corresponded to a BMI $=26$ in all groups of age, but increased its values with the increase of girls' age, shifting from $14.5 \%$ at the age of 11 years to $63 \%$ at the age of 13 years (Figure 4). This means that an overweight or obese girl has a higher probability (up to $63 \%$ at the age of 13 years) of experimenting menarche than a normal weight one. Considering the whole

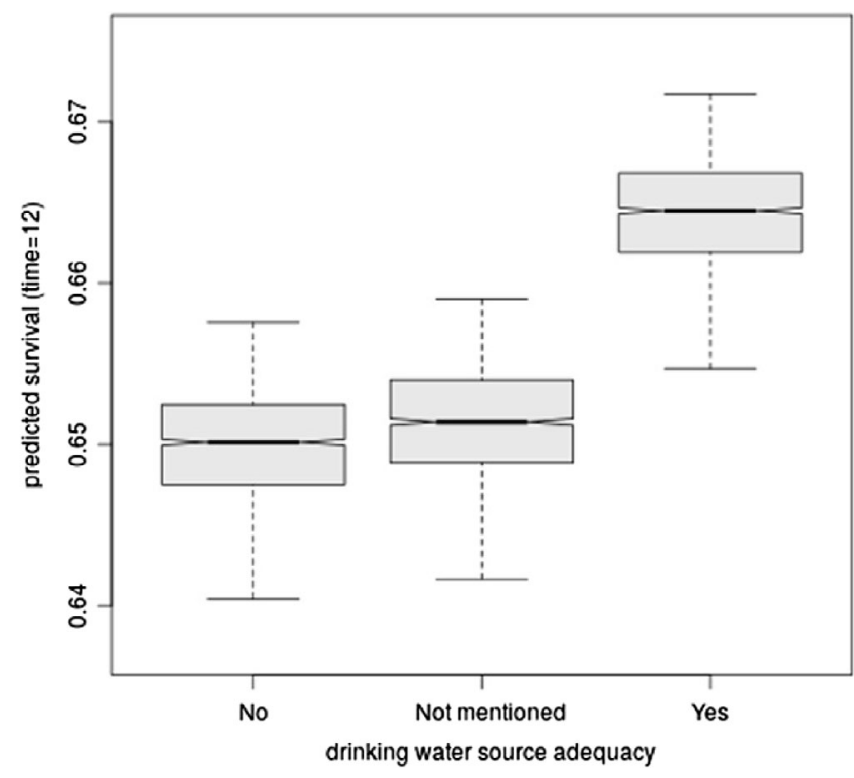

F I G URE 3 Probability of menarche occurrence according to father and mother education, at age 12 sample, and the case of girls with 12 years as an example, the girls with a BMI lower than 26 experiment menarche with a probability comprised between $28 \%$ and $40 \%$, while those with higher BMI values with an almost steady probability of $40 \%$.

\section{5 | DISCUSSION}

The results of the study showed that the probability of menarche occurrence at a certain age in a sample of Bengali girls is significantly influenced by the anthropometric features (height and BMI), as well as by some socioeconomic factors (economic status, family, and household characteristics). The observed pattern of probability remains very similar in all age groups, even if the probability values change.

\section{1 | The average age at menarche}

In the examined cohort menarche occurred, on average, at 11.8 years of age. A similar result was obtained in another recent study of the West Bengali population, where the mean age at menarche was 11.9 years (De \& Bose, 2016). The observed average age of the first menstruation is also similar to those detected in other countries. For example, among the Korean middle and highschool girls the mean age at menarche was 11.9, 11.6 in the girls from Bangladesh, and 11.4 years for the ones coming from Mexico (Han et al., 2016, Islam et al., 2017, Marván, Catillo-López, Alcalá-Herrera, \& del Callejo, 2016). Similarly, in Portugal, it was 12 years of age, 12.1
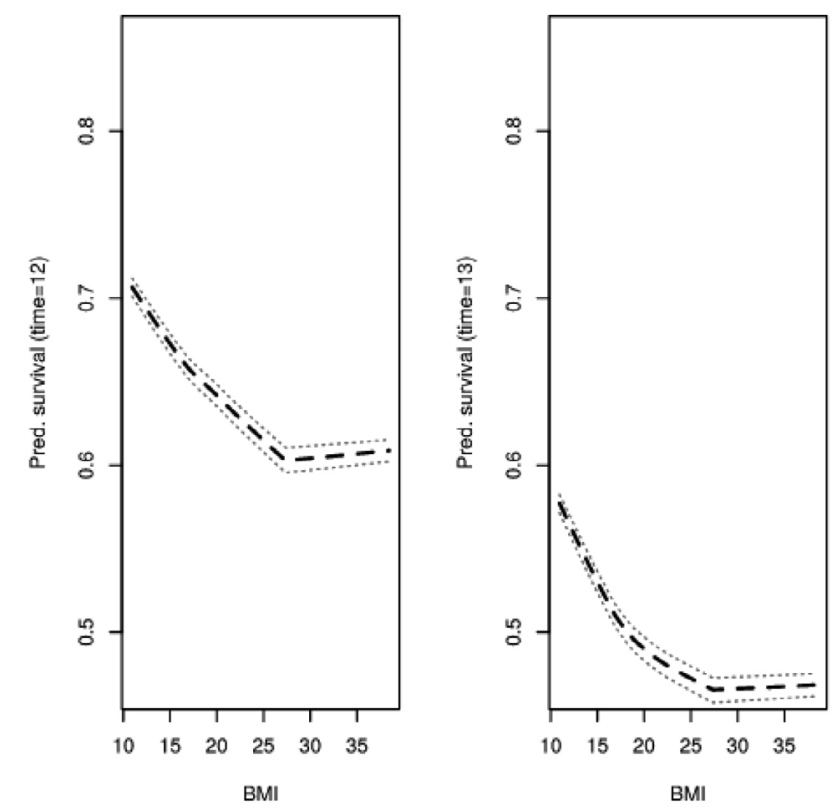

FIGURE 4 Probability of menarche occurrence according to BMI at different ages

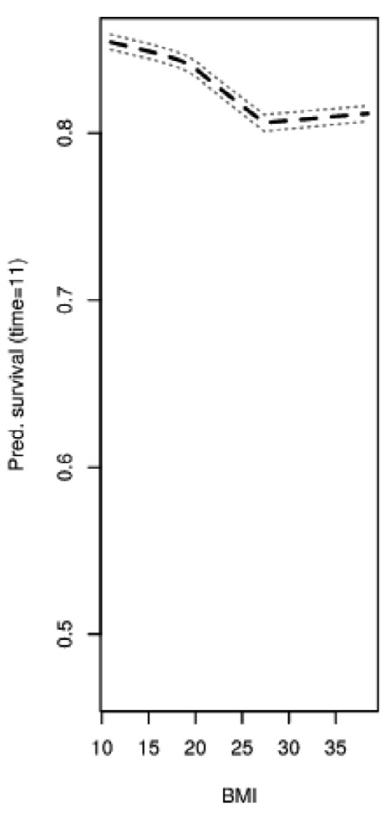

BM 
in Saudi Arabia and 12.5 in France (Lalys \& Pineau, 2014; Leitão, Rodrigues, Neves, \& Carvalho, 2013; Shaik et al., 2016).

In the same time, the mean age at menarche observed in the current study is lower than those detected in the previous researches carried out in the Indian population, thus suggesting an ongoing, negative secular trend regarding menarche age. In 2005, Pathak, Tripathi, and Subramanian (2014) examined 91394 Indian females, aged 15 to 49. Among them, the average age at menarche was 13.8, for the ones born between 1955 and 1964 and 13.6 for the girls born from 1985 to 1989. A similar mean age (13.5 years) of the first menstruation was observed in the girls from a rural area in the Amravati district of Maharashtra, examined in 2013-14 (Wasnik et al., 2015). The negative intergenerational changes in the age of menarche of Indian girls were also confirmed by John, Verma, and Chhatwal (2014) in their study on 400 middle-school Punjabi girls and their mothers. The average age at menarche was 14.3 for mothers when for daughters it was already 12.4 years of age.

The trend toward lower mean age at menarche observed in the present study is even strengthened considering that our result could represent an overestimate of the true mean age, due the possible error of retrospective data (Salehabadi, Sengupta, \& Das, 2015).

\section{2 | Influential factors on age of menarche}

The presently observed later menarche due to higher height is in line with the results of a previous study on the Indian population, in which taller girls experienced menarche later than their shorter counterparts (Bagga \& Kulkarni, 2000; John et al., 2014; Khadgawat et al., 2016). There is also a vast amount of international literature reporting that taller girls reach their menarche at a relatively earlier age (Elks et al., 2010; Koprowski, Ross, Mack, Henderson, \& Bernstein, 1999; Lin et al., 2016; Onland-Moret et al., 2005; Relethford \& Lees, 1980; Shangold, Kelly, Berkeley, Freedman, \& Groshen, 1989). It was also suggested that not only body height, but even more so the moment of the height spurt has a crucial influence on the timing of menarche (Chang, Tzeng, Cheng, \& Chie, 2000).

The mutual proportion of body height and mass also had an influence on the age of menarche. It is in line with another study where body mass, alongside nutritional status, was even distinguished as one of the factors with the strongest influence on the onset of menarche (Batubara, Soesanti, \& van de Waal, 2010). In the present study, a higher probability of a relatively earlier onset of menarche was noted in girls with a higher BMI. This is consistent with the results of other studies carried out in the Indian population. The same relationship was also observed in girls from Kuwait and Germany, Italy and Chile (Bau et al., 2009, Al-Awadhi et al., 2013). However, the exact physiological mechanism linking BMI to menarche remains unclear. It is suggested that high BMI values in the prepubertal period could lead to increased estrogen production, which in turn predisposes to an earlier occurrence of menarche (Cheng et al., 2012).

The relation between BMI, as well as other causal factors, and menarche occurrence did not change with girls' age, but the probability of menarche become stronger in higher age groups, as expected.

Besides the anthropometric characteristics, the age at menarche can also be influenced by the socio-economic environment in which the girls are growing up (Khalid et al., 2015; Lee, Kim, Oh, Lee, \& Park, 2016).

In the present study, a lower probability of menarche occurrence was observed with family expenditures increase, and with higher socio-economic, cultural, or working levels. Similarly, other studies on the Indian population noticed that females from more affluent families experience menarche later than their poorer counterparts (Pathak et al., 2014). There, the authors suggested that girls with a higher economic status were more likely to care about their figure and therefore take part in more intense physical activities, which could have reduced their body mass and shifted the age of their menarche to the upper thresholds (Pathak et al., 2014; Rees, 1993). A similar association was observed in the American population, where the relatively worse financial situation of the family was associated uniquely with earlier menarche (Deardorff, Abrams, Ekwaru, \& Rehkopf, 2014). In turn, in Poland, the increase in expenses due to the rising food prices in the 1960s was correlated with a relatively later onset of menarche (Gomula \& Koziel, 2018). However, opposite results have been obtained in other researches previously conducted in the Indian population, where the girls coming from wealthier families experienced menarche at an earlier age, compared to those growing up in less favorable economic conditions (Bagga \& Kulkarni, 2000). Similarly, in Pakistani research, girls from the highest social class experienced menarche earlier, compared to their lower-class counterparts (Ahmed, Waheed, Ahmad, \& Danish, 2016). The different direction of the association between expenditure and age of menarche observed in different periods or countries could be interpreted in relation to BMI variability and to the causal effect of BMI on menarche onset. In fact, assuming a negative relation between BMI and menarche age, it is to be noted that the association between BMI 
and socio-economic level is different in low-income (LI) and high-income (HI) countries. In fact, in LI countries the higher BMI means values are present in people from the higher economic classes (where girls could experience menarche earlier), while in HI countries in people from the lower classes (Pampel et al, 2012). In the present study, India would perform in the same way as HI countries. This hypothesis is confirmed by the results on the negative secular trend of menarche age observed in this study and similar to other countries, where was associated with socio-economic development (Lee et al., 2016; Meng et al., 2017).

However, in the present sample, not all socioeconomic factors affected the probability of menarche. In fact, household duration, or drinking water source distance did not have any significant causal effect. Similarly, among girls from Bangladesh (Islam et al., 2017) and Iran (Gharravi et al., 2008) almost no effect of socioeconomic conditions on the age of menarche was observed. At the same time, in the study of the American population, parent's occupation was one of the important factors, differentiating the onset of menarche in the studied group.

Furthermore, in contrast with the results on family expenditure, a relatively greater chance of menarche occurrence at a given age was related to the number of household's rooms and toilets. Similarly, in Chinese studies, it has been proven that a better standard of living is related to the relatively earlier occurrence of the first menstruation (Lee et al., 2007; Wang, Dang, Xing, Li, \& Yan, 2016). In the present study, the probability of menarche occurrence increased with the number of family members, sibship size, and parity of mothers, but family type did not show a significant effect. Similar results have been obtained by Khalid et al. (2015), regarding the number of family members, and by Wronka and PawlińskaChmara (2005), regarding the number of children in the family. However, a study on girls from Uganda and Nigeria showed that the number of siblings, as well as the order of births, did not have an effect on the moment of menarche (Ikaraoha et al., 2005; Odongkara Mpora et al., 2014).

In our study, girls from the "other backward class" had a higher probability of the onset of menarche at a certain age. In a previous study carried out on the Indian population, there was a statistically significant difference in the mean age at menarche between each castewomen from Forward castes statistically had their first menstruation later than their counterparts from Scheduled caste groups (Pathak et al., 2014). Also, another study of the Indian population has shown significant differences regarding age at menarche between each analyzed caste. However, girls from the Scheduled caste had menarche relatively later than their counterparts from the other caste groups (Bagga \& Kulkarni, 2000).

\section{3 | Strengths and limitations of the study}

The present study had some limitations, one of them being the use of the recall method for determining the age at menarche. According to some authors, it is possible for it not to be precise enough, due to the time interval between the menarche and the date of contact (John et al., 2014), or to represent an overestimate of the true age (Salehabadi et al., 2015). However, other studies have shown that such method of obtaining the information about the age at menarche can be sufficiently accurate (Koprowski, Coates, \& Bernstein, 2001; Must et al., 2002; Pierce \& Leon, 2005). Indeed, the parametric modelization realized by Salehabadi and Sengupta (2018) in a similar dataset has shown that, depending on the statistical model used, the recall effect can result irrelevant. Furthermore, in our research, the inclusion of girls' age in the regression model has permitted to account for the possible error due to recall data. The study also has significant strengths, such as the quite large study sample. Furthermore, body height and weight were measured by skilled operators and not recalled by the participants. It is important because the individuals with higher body mass in proportion to height tend to have underestimated BMIs based on self-reported measurements (Lawlor, Bedford, Taylor, \& Ebrahim, 2002; Pierce \& Leon, 2005). A major strength of the research is the statistical approach, which used a class of models much wider than those usually considered by regression approaches, thus improving the estimation of causal effects. Indeed, despite the cross sectional nature of the sample of Bengali girls, the Random Forest analysis allowed to measure the causal effects on the age at menarche, and not mere associations between variables as generally done.

\section{6 | CONCLUSIONS}

In the analyzed sample of Bengali girls, a complex pattern of relationship between sexual development, physique, and socio-economic characteristics was defined. The probability of menarche occurrence was significantly influenced by the anthropometric features, as well as some of the socioeconomic variables. Although the observed pattern of probability remained very similar in all age groups, the probability changed with age.

The observed tendency toward earlier menarche, along with some of the observed causal relationships, 
suggests that this sample of Indian population is performing similarly to girls from other middle and HI countries in the world.

\section{ACKNOWLEDGMENTS}

This study has been sponsored by the Neys van Hoogstraten Foundation, The Netherlands (ID158) and Indian Statistical Institute, Kolkata, India.

\section{CONFLICT OF INTEREST}

The authors declare no potential conflict of interest.

\section{AUTHOR CONTRIBUTIONS}

R.D., P.D., and A.C. carried out the field part of the research and collected the data. E.M. conceived of the presented idea with support from M.Z. S.C. performed the statistical analysis and prepared the figures with support from E.M. E.M., L.K., and M.Z. wrote the manuscript with support from S.C. E.M., L.K., and M.Z. collected the literature. All authors provided critical feedback and helped shape the research, analysis, and manuscript.

\section{ORCID}

\section{Magdalena Żegleń (1) https://orcid.org/0000-0001-6028- 8905 \\ Elisabetta Marini @ https://orcid.org/0000-0001-8779- 8745 \\ Eukasz Kryst (1D) https://orcid.org/0000-0001-6938-192X}

\section{REFERENCES}

Ahmed, S. M., Waheed, M. A., Ahmad, F., \& Danish, S. H. (2016). Factors contributing to early menarche in school girls. The Journal of the Pakistan Medical Association, 66, 629-633.

Al-Awadhi, N., Al-Kandari, N., Al-Hasan, T., AlMurjan, D., Ali, S., \& Al-Taiar, A. (2013). Age at menarche and its relationship to body mass index among adolescent girls in Kuwait. BMC Public Health, 13, 29. https://doi.org/10.1186/1471-2458-13-29

Anderson, S. E., \& Must, A. (2005). Interpreting the continued decline in the average age at menarche: Results from two nationally representative surveys of U.S. girls studied 10 years apart. The Journal of Pediatrics, 147, 753-760. https://doi.org/ 10.1016/J.JPEDS.2005.07.016

Bagga, A., \& Kulkarni, S. (2000). Age at menarche and secular trend in Maharashtrian (Indian) girls. Acta Biologica Szegediensis, 44 (1-4), 53-57.

Batubara, J. R., Soesanti, F., \& van de Waal, H. D. (2010). Age at menarche in Indonesian girls: A national survey. Acta Medica Indonesiana, 42, 78-81.

Bau, A. M., Ernert, A., Schenk, L., Wiegand, S., Martus, P., Grüters, A., \& Krude, H. (2009). Is there a further acceleration in the age at onset of menarche? A cross-sectional study in 1840 school children focusing on age and bodyweight at the onset of menarche. European Journal of Endocrinology, 160, 107-113. https://doi.org/10.1530/EJE-08-0594
Breiman, L. (2001). Random forests. Machine Learning, 45, 5-32.

Buffa, R., Floris, G., \& Marini, E. (2002). Bioelectrical impedance vector in pre-and postmenarcheal females. Nutrition, 18, 474-478.

Buffa, R., Floris, G., Marini, E., \& Ortu, A. (2003). Size and shape modifications in Sardinian adolescent girls. Anthropologischer Anzeiger, 61, 421-434.

Chang, S. H., Tzeng, S. J., Cheng, J. Y., \& Chie, W. C. (2000). Height and weight change across menarche of schoolgirls with early menarche. Archives of Pediatrics \& Adolescent Medicine, 154, 880-884.

Cheng, G., Buyken, A. E., Shi, L., Karaolis-Danckert, N., Kroke, A., Wudy, S. A., ... Remer, T. (2012). Beyond overweight: Nutrition as an important lifestyle factor influencing timing of puberty. Nutrition Reviews, 70, 133-152. https://doi.org/10.1111/j.17534887.2011.00461

Chowdhury, S., Shahabuddin, A. K. M., Shahabuddin, A. J., Seal, K. K., Talukder, Q., Hassan, R. A., ... Talukder, R. A. (2000). Nutritional status and age at menarche in a rural area of Bangladesh. Annals of Human Biology, 2, 249-256. https:// doi.org/10.1080/030144600282136

Cole, T. J. (2003). The secular trend in human physical growth: A biological view. Economics and Human Biology, 1, 161-168. https://doi.org/10.1016/S1570-677X(02)00033-3

Das, R., Das, S., Datta Banik, S., Saha, R., Chakraborty, A., \& Dasgupta, P. (2016). Secular trends in physical growth and maturation in 7 to 21 year-old Bengali boys and girls from Kolkata, India, over six decades of time interval. International Journal of Anthropology, 31, 185-226.

De Bond, J. A. P., \& Smith, J. T. (2014). Kisspeptin and energy balance in reproduction. Reproduction, 147, R53-R63. https://doi. org/10.1530/REP-13-0509

De, K., \& Bose, K. (2016). Nutritional status and menarcheal age of rural adolescent girls of salboni block of paschim Medinipur,westbengal, India. International Journal of Experimental Research and Review, 6, 36-40.

de Onis, M., Onyango, A. W., Borghi, E., Siyam, A., Nishida, C., \& Siekmann, J. (2007). Development of a WHO growth reference for school-aged children and adolescents. Bulletin of the World Health Organization, 85, 660-667.

Deardorff, J., Abrams, B., Ekwaru, J. P., \& Rehkopf, D. H. (2014). Socioeconomic status and age at menarche: An examination of multiple indicators in an ethnically diverse cohort. Annals of Epidemiology, 24, 727-733. https://doi.org/10.1016/J. ANNEPIDEM.2014.07.002

Elks, C. E., Perry, J. R. B., Sulem, P., Chasman, D. I., Franceschini, N., He, C., ... Murray, A. (2010). Thirty new loci for age at menarche identified by a meta-analysis of genomewide association studies. Nature Genetics, 42, 1077-1085. https://doi.org/10.1038/ng.714

Fernandez-Fernandez, R., Martini, A. C., Navarro, V. M., Castellano, J. M., Dieguez, C., Aguilar, E., ... Tena-Sempere, M. (2006). Novel signals for the integration of energy balance and reproduction. Molecular and Cellular Endocrinology, 254-255, 127-132. https://doi.org/10.1016/j.mce.2006.04.026

Fredriks, A. M., van Buuren, S., van Heel, W. J. M., DijkmanNeerincx, R. H. M., Verloove-Vanhorick, S. P., \& Wit, J. M. (2005). Nationwide age references for sitting height, leg length, and sitting height/height ratio, and their diagnostic value for 
disproportionate growth disorders. Archives of Disease in Childhood, 90, 807-812. https://doi.org/10.1136/adc.2004.050799

Frisch, R. E., \& Revelle, R. (1970). Height and weight at menarche and a hypothesis of critical body weights and adolescent events. Science, 169(3943), 397-399.

Gelman, A., \& Meng, X. L. (2004). Applied Bayesian modeling and causal inference from incomplete-data perspectives. Hoboken, NJ: Wiley.

Gharravi, A., Marjani, M., \& Golalipour, M. J. (2008). Correlation of age at menarche and height in Iranian student girls living in Gorgan-northeast of Iran. Journal of the Pakistan Medical Association, 58(8), 426-429.

Glueck, C. J., Morrison, J. A., Wang, P., \& Woo, J. G. (2013). Early and late menarche are associated with oligomenorrhea and predict metabolic syndrome 26 years later. Metabolism, 62(11), 1597-1606. https://doi.org/10.1016/J.METABOL.2013.07.005

Gohlke, B., \& Woelfle, J. (2009). Growth and puberty in German children: Is there still a positive secular trend? Deutsches Arzteblatt International, 106(23), 377-382. https://doi.org/10. 3238/arztebl.2009.0377

Gomula, A., \& Koziel, S. (2018). Secular trend and social variation in age at menarche among polish schoolgirls before and after the political transformation. American Journal of Human Biology, 30(1), e23048. https://doi.org/10.1002/ajhb.23048

Han, D., Lee, J., \& Kim, S. (2016). Secular trends and influencjing factors fir the early menarche among Korean middle and high school girls. Journal of Korea Contents Association, 16(3), 319-327.

He, C., Kraft, P., Chen, C., Buring, J. E., Paré, G., Hankinson, S. E., ... Chasman, D. I. (2009). Genome-wide association studies identify loci associated with age at menarche and age at natural menopause. Nature Genetics, 41(6), 724-728. https://doi.org/10. 1038/ng.385

Ikaraoha, C., Mbadiwe, I., Igwe, C., Allagua, D., Mezie, O., Iwo, G., \& Ofori, P. (2005). Menarchial age of secondary school girls in urban and rural areas of rivers state, Nigeria. Online Journal of Health Allied Sciences, 4(2), 1-4.

International Statistical Institute. (2017). Developing countries-isiweb.org. Retrieved from https:/www.isi-web.org/index.php/ resources/developing-countries

Islam, M. S., Hussain, M. A., Islam, S., Mahumud, R. A., Biswas, T., \& Islam, S. M. S. (2017). Age at menarche and its socioeconomic determinants among female students in an urban area in Bangladesh. Sexual \& Reproductive Healthcare, 12, 88-92. https://doi.org/10.1016/J.SRHC.2017.03.008

John, J., Verma, M., \& Chhatwal, J. (2014). Factors affecting menarche in Punjabi girls 141 original article physiological variables, psychosocial factors and age Indian. Indian Journal of Physiological Pharmacology, 58, 141-146.

Khadgawat, R., Marwaha, R. K., Mehan, N., Surana, V., Dabas, A., Sreenivas, V., ... Gupta, N. (2016). Age of onset of puberty in apparently healthy school girls from northern India. Indian Pediatrics, 53(5), 383-387. https://doi.org/10.1007/s13312-0160857-5

Khalid, H., Khawar, K., Fawad, M., Farhat, M., Imran, M., Shahnawaz, M., ... Humayun, A. (2015). Age of menarche in relation to Sosioeconomic status BMI, physical activity and stress among high school girls. Proceedings (Shaikh Zayed Postgraduate Medical Institute), 29, 35-40.
Khatoon, T., Kumar Verma, A., Kumari, R., Rupani, R., Singh, M., \& Rizvi, A. (2011). Original research paper age at menarche and affecting bio-social factors among the girls of Lucknow, Uttar Pradesh introduction. Journal of Indian Academy of Forensic Medicine, 33(3), 221-223.

Klein, J. P., \& Moeschberger, M. L. (2003). Survival analysis: Techniques for censored and truncated data. New York, NY: Springer-Verlag.

Koprowski, C., Coates, R. J., \& Bernstein, L. (2001). Ability of young women to recall past body size and age at menarche. Obesity Research, 9(8), 478-485. https://doi.org/10.1038/oby.2001.62

Koprowski, C., Ross, R. K., Mack, W. J., Henderson, B. E., \& Bernstein, L. (1999). Diet, body size and menarche in a multiethnic cohort. British Journal of Cancer, 79(11-12), 1907-1911. https://doi.org/10.1038/sj.bjc.6690303

Koury, J. C., Ribeiro, M. A., Massarani, F. A., Vieira, F., \& Marini, E. (2019). Fat-free mass in adolescent athletes: Accuracy of bioimpedance equations and identification of new predictive equations. Nutrition, 60, 59-65.

Kowal, M., Kryst, Ł., Woronkowicz, A., \& Sobiecki, J. (2014). Longterm changes in body composition and prevalence of overweight and obesity in girls (aged 3-18 years) from Kraków (Poland) from 1983, 2000 and 2010. Annals of Human Biology, 41(5), 415-427. https://doi.org/10.3109/03014460.2013.878394

Kryst, Ł., Kowal, M., Woronkowicz, A., Sobiecki, J., \& Cichocka, B. A. (2012). Secular changes in height, body weight, body mass index and pubertal development in male children and adolescents in Krakow, Poland. Journal of Biosocial Science, 44(04), 495-507. https://doi.org/10.1017/S0021932011000721

Laitinen, J., Power, C., \& Järvelin, M. R. (2001). Family social class, maternal body mass index, childhood body mass index, and age at menarche as predictors of adult obesity. The American Journal of Clinical Nutrition, 74(3), 287-294.

Lalys, L., \& Pineau, J.-C. (2014). Age at menarche in a group of French schoolgirls. Pediatrics International, 56(4), 601-604. https://doi.org/10.1111/ped.12296

Lawlor, A. D., Bedford, C., Taylor, M., \& Ebrahim, S. (2002). Agreement between measured and self-reported weight in older women. Results from the British Women's heart and health. Age and Ageing, 31, 169-174.

Lee, J. M., Appugliese, D., Kaciroti, N., Corwyn, R. F., Bradley, R. H., \& Lumeng, J. C. (2007). Weight status in young girls and the onset of puberty. PEDIATRICS, 119(3), e624-e630.

Lee, M., Kim, S. H., Oh, M., Lee, K. W., \& Park, M. J. (2016). Age at menarche in Korean adolescents: Trends and influencing factors. Reproductive Health, 13(1), 121.

Leitão, R. B., Rodrigues, L. P., Neves, L., \& Carvalho, G. S. (2013). Development of adiposity, obesity and age at menarche: An 8-year follow-up study in Portuguese schoolgirls. Iternational Journal of Adolescent Medicine and Health, 25(1), 55-63.

Lin, L. L., Zheng, B., Lyu, J., Guo, Y., Bian, Z., Yu, C. Q., ... China Kadoorie Biobank (CKB) Collaborative Group. (2016). Association between age at menarche and height and leg length in adult women: Findings from survey in 10 areas in China. Zhonghua Liuxingbingxue Zazhi, 37(11), 1454-1458. https://doi. org/10.3760/cma.j.issn.0254-6450.2016.11.004

Lu, M., Sadiq, S., Feaster, D. J., \& Ishwaran, H. (2018). Estimating individual treatment effect in observational data using random Forest methods. Journal of Computational and Graphical 
Statistics, 27(1), 209-219. https://doi.org/10.1080/10618600. 2017.1356325

Marván, M. L., Catillo-López, R. L., Alcalá-Herrera, V., \& del Callejo, D. (2016). The decreasing age at menarche in Mexico. Journal of Pediatric and Adolescent Gynecology, 29(5), 454-457. https://doi.org/10.1016/J.JPAG.2016.02.006

Meng, X., Li, S., Duan, W., Sun, Y., \& Jia, C. (2017). Secular trend of age at menarche in Chinese adolescents born from 1973 to 2004. Pediatrics, 140(2), e20170085. https://doi.org/10.1542/ peds.2017-0085

Mogensen, U. B., Ishwaran, H., \& Gerds, T. A. (2012). Evaluating random forests for survival analysis using prediction error curves. Journal of Statistical Software, 50(11), 1-23.

Must, A., Phillips, S. M., Naumova, E. N., Blum, M., Harris, S., Dawson-Hughes, B., \& Rand, W. M. (2002). Recall of early menstrual history and Menarcheal body size: After 30 years, how well do women remember? American Journal of Epidemiology, 155(7), 672-679. https://doi.org/10.1093/aje/155.7.672

Odongkara Mpora, B., Piloya, T., Awor, S., Ngwiri, T., Laigong, P., Mworozi, E. A., \& Hochberg, Z. (2014). Age at menarche in relation to nutritional status and critical life events among rural and urban secondary school girls in post-conflict northern Uganda. BMC Women's Health, 14(1), 66. https://doi.org/10. 1186/1472-6874-14-66

Onland-Moret, N. C., Peeters, P. H. M., van Gils, C. H., ClavelChapelon, F., Key, T., Tjønneland, A., ... Riboli, E. (2005). Age at menarche in relation to adult height. American Journal of Epidemiology, 162(7), 623-632. https://doi.org/10.1093/aje/kwi260

Pampel, F. C., Denney, J. T., \& Krueger, P. M. (2012). Obesity, SES, and Economic Development: A Test of the Reversal Hypothesis. Social Science and Medicine, 74(7), 1073-1081.

Parsons, T. J., Power, C., Logan, S., \& Summerbell, C. D. (1999). Childhood predictors of adult obesity: A systematic review. International Journal of Obesity and Related Metabolic Disorders, 23(Suppl 8), S1-S107.

Pathak, P. K., Tripathi, N., \& Subramanian, S. V. (2014). Secular trends in Menarcheal age in India-evidence from the Indian human development survey. PLoS One, 9(11), e111027. https:// doi.org/10.1371/journal.pone.0111027

Pierce, M. B., Kuh, D., \& Hardy, R. (2012). The role of BMI across the life course in the relationship between age at menarche and diabetes, in a British birth cohort. Diabetic Medicine, 29(5), 600-603. https://doi.org/10.1111/j.1464-5491.2011.03489.x

Pierce, M. B., \& Leon, D. A. (2005). Age at menarche and adult BMI in the Aberdeen children of the 1950s cohort study. The American Journal of Clinical Nutrition, 82(4), 733-739. https://doi. org/10.1093/ajcn/82.4.733

Rees, M. (1993). Menarche when and why? Lancet, 342(8884), 1375-1376. https://doi.org/10.1016/0140-6736(93)92746-G
Relethford, J., \& Lees, F. (1980). The effects of ageing and secular trend on stature in rural western Ireland. American Journal of Physical Anthropology, 55, 81-88.

Salehabadi, S. M., \& Sengupta, D. (2018). Recent advances in the statistical analysis of retrospective time-to-event data. In R. Dasgupta (Ed.), Advances in growth curve and structural equation Modeling. Singapore: Springer.

Salehabadi, S. M., Sengupta, D., \& Das, R. (2015). Parametric estimation of Menarcheal age distribution based on recall data. Scandinavian Journal of Statistics, 42, 290-305.

Shaik, S., Hashim, R., Alsukait, S., Abdulkader, G., AlSudairy, H., AlShaman, L., ... Fouda Neel, M. (2016). Assessment of age at menarche and its relation with body mass index in school girls of Riyadh, Saudi Arabia. Asian Journal of Medical Sciences, 7 (2), 5-12.

Shangold, M. M., Kelly, M., Berkeley, A. S., Freedman, K. S., \& Groshen, S. (1989). Relationship between menarcheal age and adult height. Southern Medical Journal, 82(4), 443-445.

Talma, H., Schönbeck, Y., van Dommelen, P., Bakker, B., van Buuren, S., \& HiraSing, R. A. (2013). Trends in Menarcheal age between 1955 and 2009 in The Netherlands. PLoS One, 8(4), e60056. https://doi.org/10.1371/journal.pone.0060056

Wang, Z., Dang, S., Xing, Y., Li, Q., \& Yan, H. (2016). Correlation of body mass index levels with menarche in adolescent girls in Shaanxi, China: A cross sectional study. BMC Women's Health, 16(1), 61. https://doi.org/10.1186/s12905-016-0340-4

Wasnik, V. R., Dhumale, D., \& Jawarkar, A. K. (2015). A study of the menstrual pattern and problems among rural school going adolescent girls of Amravati district of Maharashtra, India. International Journal of research in Medical Sciences, 33, 1252-1256.

Weiner, J. S., \& Lourie, J. A. (1969). IBP (international biological programme) human biology. A guide to field methods. UK: Blackwell Scientific Publications.

World Health Organization. (2000). Obesity: Preventing and managing the global epidemic (No. 894). Geneva, Switzerland: Author.

Wronka, I., \& Pawlińska-Chmara, R. (2005). Menarcheal age and socio-economic factors in Poland. Annals of Human Biology, 32 (5), 630-638.

How to cite this article: Żegleń M, Marini E, Cabras $\mathrm{S}$, et al. The relationship among the age at menarche, anthropometric characteristics, and socio-economic factors in Bengali girls from Kolkata, India. Am J Hum Biol. 2019; 23380. https://doi.org/10.1002/ajhb.23380 